\title{
Colheita e armazenamento de sementes de coentro
}

\author{
Warley Marcos Nascimento(1), Roseane Sousa Pereira(1), Raquel Alves de Freitas ${ }^{(1)}$, \\ Lucimara Blumer(1) e Marlove Fátima Brião Muniz ${ }^{(2)}$
}

\begin{abstract}
(1)Embrapa Hortaliças, BR 060, Km 9, Caixa Postal 218, CEP 70359-970 Brasília, DF. E-mail: wmn@cnph.embrapa.br, rose@cnph.embrapa.br, raquel@cnph.embrapa.br, lublumer@yahoo.com.br (2)Universidade Federal de Santa Maria, Dep. de Defesa Fitossanitária, CEP 97105-900 Santa Maria, RS. E-mail: marlove@smail.ufsm.br
\end{abstract}

Resumo - Este trabalho teve por objetivos avaliar a qualidade física e fisiológica de sementes de coentro (Coriandrum sativum) colhidas manual e mecanicamente, bem como a qualidade fisiológica e sanitária das sementes inteiras e partidas, armazenadas em diferentes embalagens e condições de ambiente. Sementes de coentro cultivar Verdão foram colhidas manual e mecanicamente. Depois do beneficiamento, foi determinada a porcentagem de pureza, e as sementes foram separadas em sementes inteiras (diaquênios) e partidas (aquênios). As sementes foram acondicionadas em embalagens semipermeáveis e impermeáveis e armazenadas durante 12 meses em condições ambientais e em câmara fria $\left(10^{\circ} \mathrm{C}, 45 \% \mathrm{UR}\right)$. A qualidade fisiológica - teste de germinação, primeira contagem, envelhecimento acelerado e emergência das plântulas em casa de vegetação - e sanitária foi avaliada aos 0, 3, 6, 9 e 12 meses de armazenamento. A colheita mecânica apresentou maior porcentagem de sementes partidas. Sementes inteiras, colhidas mecanicamente, apresentaram maior vigor que as sementes inteiras colhidas manualmente. As sementes de coentro conservaram a qualidade até um ano, independentemente das condições de armazenamento. Quanto ao armazenamento em condições ambientais, as sementes devem ser acondicionadas em embalagens impermeáveis. Sementes partidas apresentam potencial para o estabelecimento da cultura de coentro.

Termos para indexação: Coriandrum sativum, qualidade de sementes, produção.

\section{Harvesting and storage of coriander seeds}

\begin{abstract}
This study aimed to evaluate the physical and physiological quality of coriander (Coriandrum sativum) seeds harvested manually and mechanically, as well as the physiological and sanitary quality of whole and split seeds stored in different containers and storage conditions. 'Verdão' coriander seeds were harvested manually and mechanically. After conditioning, seed purity was determined, and the seeds were separated in two classes: whole seeds (deachenes) and split seeds (achenes). Seeds were placed into semipermeable and impermeable containers and stored for twelve months under environment and cold chamber conditions $\left(10^{\circ} \mathrm{C}, 45 \% \mathrm{RH}\right)$. Physiological and sanitary seed quality (germination, first counting, accelerated aging and seedling emergence in greenhouse) were evaluated at 0, 3, 6, 9 and 12 months of storage. Mechanical harvesting increased split seeds. Whole seeds harvested mechanically had higher vigor than whole seeds harvested manually. Coriander seeds maintain physiological quality up to one year in any storage conditions. However, for uncontrolled storage conditions, seeds may be placed in hermetic containers. Split seeds of coriander show potential to stand establishment.
\end{abstract}

Index terms: Coriandrum sativum, seed quality, production.

\section{Introdução}

O coentro (Coriandrum sativum) é uma hortaliça muito apreciada, e é uma planta condimentar largamente utilizada no Brasil. A produção de sementes de coentro encontra-se em plena expansão (Trigo et al., 1997). O diaquênio do coentro é um fruto-semente constituído de dois aquênios, geralmente comercializado inteiro. No entanto, em algumas regiões, os produtores dividem os frutos, obtendo sementes partidas, para maior rendimento de semeadura e, em alguns casos, para obter melhoria na germinação (Nascimento, 2004).

Durante a fase de produção de sementes, a colheita pode ser realizada manualmente, cortando-se os ramos com as umbelas. Essa tecnologia é bastante empregada no Brasil, para a produção de sementes de coentro, geralmente em pequenas áreas.Esse procedimento poderá acarretar a queda da produção e da qualidade das sementes, pois, em virtude do baixo rendimento dessa 
operação, as sementes ficam expostas às intempéries climáticas por um período maior.

No entanto, em algumas regiões, notadamente no Centro-Oeste, sementes de coentro têm sido produzidas em áreas extensas sob pivô central. Nessas áreas pode ser viável a utilização de colheita mecanizada. No que tange às sementes de capim-colonião, a colheita manual fornece sementes que, embora de menor pureza física, apresentam qualidade fisiológica superior, comparadas com sementes provenientes de colheita mecânica (Maschietto et al., 2003). Não existem muitos estudos que buscam viabilizar a colheita mecânica de sementes de coentro.

Ante a defasagem entre as épocas de colheita e de semeadura, o armazenamento constitui etapa praticamente obrigatória de um programa de produção de sementes. A principal preocupação durante o período de armazenamento é a preservação da qualidade das sementes, por isso, busca-se minimizar a velocidade do processo de deterioração, uma vez que um dos sintomas desse processo é a queda do seu potencial de armazenamento (Delouche \& Baskin, 1973).

Durante o armazenamento, a umidade relativa do ar tem relação direta com o grau de umidade das sementes, enquanto a temperatura influencia a velocidade dos processos bioquímicos (Delouche et al., 1973). Portanto, as melhores condições para manutenção da qualidade de sementes ortodoxas, tais como o coentro, são baixa umidade relativa do ar e baixa temperatura. Nessas condições, o embrião mantém menor atividade metabólica (Carvalho \& Nakagawa, 2000). O tipo de embalagem utilizada no acondicionamento das sementes, durante o armazenamento, também assume grande importância na preservação da sua qualidade (Crochemore, 1993).

Em sementes de abóbora, Bee \& Barros (1999) verificaram que é viável o uso de embalagens a vácuo para o armazenamento das sementes. $\mathrm{O}$ acondicionamento de sementes de pimentão, em embalagens de papelalumínio, conservou melhor as sementes em comparação com embalagens de polietileno (Oladiran \& Agunbiabe, 2000). Tem-se observado recentemente a comercialização de sementes de coentro em embalagens (caixas) de papelão. Na escolha da embalagem, devem ser consideradas, também, as condições ambientais nas quais as sementes serão armazenadas (Carvalho \& Nakagawa, 2000). O tipo de embalagem não interfere na qualidade das sementes de maxixe, durante o armazenamento por doze meses, tanto em condições ambientais quanto em câmara fria (Torres et al., 2002). Já sementes de melancia mantêm sua qualidade fisiológica durante 12 meses, quando armazenadas em condições de câmara fria, independentemente do tipo de embalagem de acondicionamento (Torres, 2005). Dados relacionados com a tecnologia de produção de sementes de coentro são ainda escassos.

O objetivo deste trabalho foi avaliar a qualidade física e fisiológica de sementes de coentro, colhidas manual e mecanicamente, bem como avaliar a qualidade fisiológica e sanitária das sementes inteiras e partidas, armazenadas em diferentes embalagens e condições de ambiente.

\section{Material e Métodos}

No primeiro experimento, avaliou-se a influência do método de colheita na qualidade física e fisiológica de sementes de coentro. O ensaio foi realizado em um campo de produção de sementes de coentro da cultivar Verdão, localizado em Luziânia, GO, em 2003.

Uma parte do campo de sementes foi colhida manualmente (colheita única), cortando-se as umbelas e trilhando-as manualmente. Outra parte foi colhida mecanicamente. Para tanto, utilizou-se uma colheitadeira Case IH Axial-Flow 2388, operada na segunda marcha $\left(3 \mathrm{~km} \mathrm{~h}^{-1}\right)$, com uma rotação de $2.350 \mathrm{rpm}$ (motor), $500 \mathrm{rpm}$ (rotor) e $900 \mathrm{rpm}$ (ventilador).

A umidade das sementes por ocasião da colheita foi de $6,1 \%$. As sementes foram beneficiadas manualmente e, depois do beneficiamento, as sementes oriundas dos dois tratamentos foram submetidas aos seguintes testes: pureza, germinação, primeira contagem, envelhecimento acelerado e emergência de plântulas em casa de vegetação.

Para a determinação da pureza, pesaram-se $40 \mathrm{~g}$ de cada tratamento, separando-se os diferentes componentes da amostra. Determinou-se, também, a porcentagem de sementes partidas (aquênios).

Na determinação da germinação, quatro subamostras de 50 sementes de cada tratamento foram distribuídas sobre duas folhas de papel mata-borrão, umedecido com água na proporção de 2,5 vezes a massa do papel seco; as subamostras foram dispostas em caixas de plástico tipo gerbox, mantidas em germinador a $20-30^{\circ} \mathrm{C}$. A avaliação da porcentagem de sementes germinadas (emissão da raiz primária) foi realizada aos 7 e 15 dias depois da instalação do teste (Brasil, 1992). 
A primeira contagem foi realizada com o teste de germinação, contabilizando-se o número de plântulas germinadas no sétimo dia depois do início do teste.

Na determinação do envelhecimento acelerado, utilizou-se o método proposto pela Association of Official Seed Analysts (1983). Foram distribuídos 4 g de sementes sobre uma tela de alumínio fixada em caixa de plástico tipo gerbox, contendo, ao fundo, $40 \mathrm{~mL}$ de solução saturada de $\mathrm{NaCl}\left(40 \mathrm{~g}\right.$ de $\mathrm{NaCl} 100 \mathrm{~mL}^{-1}$ de água), conforme Jianhua \& McDonald (1996). As caixas contendo as sementes foram fechadas e mantidas a $41^{\circ} \mathrm{C}$, por 72 horas. Depois desse período, as sementes foram submetidas ao teste de germinação, conforme descrito.

A avaliação da porcentagem de plântulas normais foi realizada sete dias depois da instalação do teste. Foi determinado, também, o grau de umidade das sementes depois do período de envelhecimento, visando à avaliação da uniformidade das condições do teste. A maior variação entre os tratamentos, com relação ao grau de umidade das sementes, verificado depois do teste de envelhecimento acelerado, foi de 3,6\%. Este valor está dentro do limite de 3 a 4\% considerado tolerável para condução do teste (Marcos Filho, 1999).

A avaliação da emergência das plântulas em casa de vegetação foi feita com quatro subamostras de 50 sementes de cada tratamento, as quais foram semeadas em bandejas multicelulares de poliestireno expandido (isopor), contendo 200 células preenchidas com substrato comercial (Plantmax). As caixas foram mantidas em casa de vegetação, e a avaliação das plântulas foi realizada aos 21 dias após a semeadura.

$\mathrm{O}$ experimento foi conduzido em delineamento inteiramente casualizado, com quatro repetições. Os resultados obtidos foram submetidos à análise estatística descritiva.

Para avaliar a qualidade fisiológica e sanitária das sementes inteiras e partidas, armazenadas em diferentes embalagens e condições de ambiente, realizou-se um segundo experimento, no qual as sementes de coentro da cultivar Verdão, colhidas mecanicamente, foram separadas em sementes inteiras (diaquênios) e sementes partidas (aquênios). Metade de cada uma dessas categorias de sementes foi acondicionada em embalagens semipermeáveis (caixas de papelão), e a outra metade foi acondicionada em embalagens impermeáveis (sacos aluminizados) e armazenadas, por 12 meses, em câmara fria $\left(10^{\circ} \mathrm{C}\right.$ e $45 \%$ de umidade relativa) e em condições de laboratório. Inicialmente e a cada três meses, as sementes foram avaliadas quanto à germinação (teste de germinação) e vigor (primeira contagem, envelhecimento acelerado e emergência das plântulas em casa de vegetação), conforme os procedimentos descritos no primeiro experimento.

Depois de cada período de armazenamento, foi também avaliada a qualidade sanitária das sementes, utilizando-se o método "blotter test" (papel-filtro). Duzentas sementes por tratamento foram distribuídas em gerbox, sobre três folhas de papel-filtro umedecidas com água destilada. Em seguida, as sementes foram incubadas a $25^{\circ} \mathrm{C}$ por sete dias, com fotoperíodo de 12 horas. Depois de 24 horas de incubação, a germinação das sementes foi inibida por congelamento em freezer $\left(-20^{\circ} \mathrm{C}\right)$, por 24 horas, e foram incubadas novamente a $25^{\circ} \mathrm{C}$. A análise dos fungos associados às sementes foi realizada de acordo com suas características morfológicas. Os resultados foram expressos em porcentagem de sementes infectadas por fungos.

O experimento foi conduzido no delineamento inteiramente casualizado, com quatro repetições, analisado num esquema de fatorial $5 \times 2 \times 2 \times 2$ : cinco períodos de armazenamento ( 0 , 3, 6, 9 e 12 meses), duas categorias de sementes (inteiras e partidas), dois tipos de embalagens (papel aluminizado e caixa de papelão), duas condições de armazenamento (condição ambiente e câmara fria). Os dados não foram transformados, por terem atendido às pressuposições dos testes de normalidade e de homogeneidade. Em seguida, foram submetidos à análise de variância, e a comparação entre a qualidade fisiológica das duas categorias de sementes, acondicionadas nos dois tipos de embalagens e duas condições de armazenamento, foi efetuada pelo teste de Tukey, a 5\% de probabilidade. No período de armazenamento, foi aplicada a análise de regressão polinomial até segundo grau.

\section{Resultados e Discussão}

A colheita mecânica apresentou, como esperado, menor porcentagem de pureza (76\%) do que a colheita manual (97,3\%). Além das impurezas, principalmente restos de umbelas e de plantas, observou-se maior porcentagem de sementes partidas (6,6\%) presentes na colheita mecânica, em comparação à colheita manual $(0,3 \%)$. Por isso, durante a trilha ou debulha, recomendase cuidado para evitar que os frutos sejam divididos ao meio. No entanto, durante a limpeza e classificação das 
sementes, essas metades dos frutos (aquênios) são facilmente retiradas com as impurezas (Viggiano, 1984).

Não houve variação em termos de germinação e emergência de plântulas, em casa de vegetação, entre os dois tipos de colheita (Tabela 1). No entanto, sementes colhidas manualmente apresentaram menor vigor, quando comparadas com as sementes provenientes de colheita mecânica, conforme se verifica nos resultados de envelhecimento acelerado. Sementes colhidas mecanicamente, provavelmente por terem sofrido alguns impactos incapazes de causar dano mecânico, apresentaram aumento na velocidade de germinação devido ao estresse físico sofrido e ao aumento de absorção de água. No entanto, Maschietto et al. (2003) verificaram que a colheita manual de sementes de capim-colonião fornece sementes que, embora de menor pureza física, apresentam qualidade fisiológica superior, quando comparadas com sementes provenientes de colheita mecânica. Sementes de milhodoce colhidas mecanicamente apresentam maiores danos e redução significativa no vigor (Nascimento et al., 1994).

Na Tabela 2, pode-se observar o desdobramento da interação embalagem $\mathrm{x}$ tipo de semente $\mathrm{x}$ período de armazenamento, em cada temperatura de armazenamento. Essa interação foi comprovada pela análise de variância, procedendo-se, então, à decomposição dos graus de liberdade da interação.

O tipo de embalagem afetou a germinação das sementes inteiras de coentro somente no armazenamento em condições ambientais por 12 meses (Tabela 2). $\mathrm{O}$ armazenamento em embalagem de papel aluminizado proporcionou maior porcentual de germinação, em relação às sementes armazenadas em caixa de papelão. Assim, sementes de coentro, que vêm sendo comercializadas nessas embalagens por algumas empresas, poderão ter sua qualidade fisiológica comprometida, depois de determinado período.

Tabela 1. Médias e desvios-padrão, em porcentagem, obtidos nos testes de germinação, primeira contagem de germinação, envelhecimento acelerado e emergência das plântulas em casa de vegetação, de sementes de coentro colhidas mecanicamente e manualmente.

\begin{tabular}{lcccc}
\hline Colheita & $\begin{array}{c}\text { Germinação } \\
(\%)\end{array}$ & $\begin{array}{c}\text { Primeira } \\
\text { contagem } \\
(\%)\end{array}$ & $\begin{array}{c}\text { Envelhecimento } \\
\text { acelerado } \\
(\%)\end{array}$ & $\begin{array}{c}\text { Emergência } \\
\text { de plântulas } \\
(\%)\end{array}$ \\
\hline Mecânica & $99 \pm 1,00$ & $98 \pm 1,00$ & $71 \pm 3,00$ & $92 \pm 2,52$ \\
Manual & $99 \pm 1,15$ & $93 \pm 3,78$ & $58 \pm 4,32$ & $83 \pm 5,82$ \\
\hline
\end{tabular}

Nas sementes armazenadas em câmara fria, a germinação não sofreu influência dos fatores estudados (Tabela 2). Assim, o armazenamento em câmara fria, como esperado, contribuiu para reduzir a velocidade dos processos deteriorantes de sementes acondicionadas em embalagens permeáveis. Em cebola, Caneppele et al. (1995) observaram que sementes acondicionadas em embalagens impermeáveis (aluminizado flexível e lata) mantiveram o vigor por 12 meses de armazenamento, independentemente do ambiente de armazenamento. No entanto, sementes acondicionadas em embalagens de pano, PVC com papel, polietileno rígido ou polietileno flexível, não se mostraram eficientes num período longo de armazenamento, em condições desfavoráveis de temperatura e umidade relativa do ar. Assim, a escolha do tipo de embalagem dependerá, também, das condições climáticas do ambiente de armazenamento. Isto é muito importante, pois, na maior parte dos casos, as sementes ficam expostas na prateleira da revenda em condições não controladas, ficando sujeitas às variações climáticas.

Quanto à germinação (Tabela 2), sementes partidas acondicionadas em caixas de papelão e armazenadas por 12 meses, em condições ambientais, mostraram-se superiores às sementes inteiras. No teste de primeira contagem, no início do armazenamento (0 mês), sementes partidas apresentaram maior vigor (Tabela 2). Pereira et al. (2005) também observaram aumento na velocidade de germinação nas sementes partidas de coentro. Esse aumento na velocidade de germinação de sementes partidas ocorre, provavelmente, em conseqüência da absorção mais rápida de água nessas sementes. Assim, a utilização de sementes partidas pode vir a ser utilizada comercialmente.

O maior vigor das sementes partidas, determinado pelo teste de primeira contagem, foi constatado também aos 3, 9 e 12 meses de armazenamento, em sementes acondicionadas em caixas de papelão (Tabela 2). À semelhança do que ocorreu no teste de germinação, observa-se, pelos dados obtidos na primeira contagem, que sementes inteiras acondicionadas em caixa de papelão e armazenadas em condições ambientais, por 12 meses, apresentaram menor desempenho quando comparadas às sementes acondicionadas em embalagem aluminizada.

Os testes de envelhecimento acelerado e a emergência de plântulas em casa de vegetação raras vezes mostraram diferenças entre os diversos fatores estudados. Além disso, não houve concordância entre 
estes testes quanto à indicação das sementes de mais alto vigor (Tabela 2). Aos seis meses de armazenamento, sementes inteiras acondicionadas em embalagem de papelão, quando armazenadas em condições ambientais, apresentaram maior vigor, em relação às sementes partidas, pelo teste de envelhecimento acelerado. Entretanto, o mesmo teste mostrou que, quando armazenadas em câmara fria, sementes partidas acondicionadas em alumínio foram as mais vigorosas.

Pelo teste de emergência das plântulas em casa de vegetação, sementes inteiras acondicionadas em papelão apresentaram-se superiores às sementes partidas, armazenadas por três meses em condições ambientais, ao passo que, aos 12 meses de armazenamento, nessas mesmas condições, sementes partidas mostraram-se superiores.

No teste de germinação, observa-se que, nas sementes armazenadas em condições ambientais, o efeito do período de armazenamento ocorreu apenas em sementes acondicionadas em caixas de papelão (Figura 1). Ainda com relação ao teste de germinação, verifica-se que, no armazenamento em câmara fria, houve efeito do período de armazenamento na germinação somente em sementes partidas acondicionadas em caixas de papelão. Observa-se tendência de queda na germinação, a partir dos seis meses de armazenamento, principalmente em sementes inteiras armazenadas em condições ambientais.

As médias obtidas nos testes de primeira contagem e envelhecimento acelerado (Figuras 1 e 2, respectivamente) ajustaram-se aos modelos quadráticos de regressão. Ao final de 12 meses de armazenamento, o vigor das sementes permaneceu alto nas duas condições de armazenamento. $\mathrm{O}$ armazenamento de sementes de maxixe, por 12 meses, tanto em condições ambientais, quanto em câmara fria, também conservou a qualidade fisiológica das sementes, independentemente do tipo de embalagem utilizada em seu acondicionamento (Torres et al., 2002). Em melancia, no entanto, Torres (2005) verificou que o armazenamento de sementes em câmara fria manteve melhor a qualidade fisiológica das sementes, quando comparado com o armazenamento em condições ambientais.

Quanto ao teste de emergência de plântulas em casa de vegetação, verificou-se redução linear na porcentagem de emergência, com o aumento do período de

Tabela 2. Valores médios obtidos nos teste de germinação, primeira contagem de germinação, envelhecimento acelerado e emergência das plântulas em casa de vegetação, de duas categorias de sementes de coentro acondicionadas em dois tipos de embalagens, mantidas em duas condições de armazenamento, nos diferentes períodos de armazenamento ${ }^{(1)}$.

\begin{tabular}{|c|c|c|c|c|c|c|c|c|c|c|c|}
\hline \multirow{3}{*}{$\begin{array}{l}\text { Condição de } \\
\text { armazenamento }\end{array}$} & \multirow[t]{3}{*}{ Embalagem } & \multicolumn{10}{|c|}{ Período de armazenamento (meses) } \\
\hline & & \multicolumn{2}{|c|}{0} & \multicolumn{2}{|c|}{3} & \multicolumn{2}{|c|}{6} & \multicolumn{2}{|c|}{9} & \multicolumn{2}{|c|}{12} \\
\hline & & $\begin{array}{c}\text { Sementes } \\
\text { inteiras }\end{array}$ & $\begin{array}{c}\text { Sementes } \\
\text { partidas }\end{array}$ & $\begin{array}{c}\text { Sementes } \\
\text { inteiras }\end{array}$ & $\begin{array}{c}\text { Sementes } \\
\text { partidas }\end{array}$ & $\begin{array}{c}\text { Sementes } \\
\text { inteiras }\end{array}$ & $\begin{array}{c}\text { Sementes } \\
\text { partidas }\end{array}$ & $\begin{array}{c}\text { Sementes } \\
\text { inteiras }\end{array}$ & $\begin{array}{c}\text { Sementes } \\
\text { partidas }\end{array}$ & $\begin{array}{c}\text { Sementes } \\
\text { inteiras }\end{array}$ & $\begin{array}{c}\text { Sementes } \\
\text { partidas }\end{array}$ \\
\hline & & \multicolumn{10}{|c|}{ Germinação (\%) } \\
\hline \multirow[t]{2}{*}{ Ambiente } & Alumínio & 94Aa & 94Aa & $95 \mathrm{Aa}$ & 96Aa & $95 \mathrm{Aa}$ & $97 \mathrm{Aa}$ & $95 \mathrm{Aa}$ & $98 \mathrm{Aa}$ & 93Aa & 97Aa \\
\hline & Papelão & 94Aa & $94 \mathrm{Aa}$ & $93 \mathrm{Aa}$ & 98Aa & $95 \mathrm{Aa}$ & $98 \mathrm{Aa}$ & 94Aa & 97Aa & $83 \mathrm{Bb}$ & 93Aa \\
\hline \multirow{2}{*}{ Câmara fria } & Alumínio & $94 \mathrm{Aa}$ & $94 \mathrm{Aa}$ & $97 \mathrm{Aa}$ & $98 \mathrm{Aa}$ & $96 \mathrm{Aa}$ & 94Aa & $95 \mathrm{Aa}$ & $98 \mathrm{Aa}$ & 96Aa & 94Aa \\
\hline & Papelão & 94Aa & $94 \mathrm{Aa}$ & $96 \mathrm{Aa}$ & 98Aa & 97Aa & $96 \mathrm{Aa}$ & 94Aa & 97Aa & 96Aa & 94Aa \\
\hline \multirow{3}{*}{ Ambiente } & & \multicolumn{10}{|c|}{ Primeira contagem $(\%)$} \\
\hline & Alumínio & $59 \mathrm{Ba}$ & 66Aa & 94Aa & 95Aa & $95 \mathrm{Aa}$ & $95 \mathrm{Aa}$ & 91Aa & 97Aa & $87 \mathrm{Ba}$ & 97Aa \\
\hline & Papelão & $59 \mathrm{Ba}$ & $66 \mathrm{Aa}$ & $91 \mathrm{Ba}$ & $98 \mathrm{Aa}$ & 94Aa & 97Aa & $87 \mathrm{Ba}$ & $96 \mathrm{Aa}$ & $80 \mathrm{Bb}$ & 91Aa \\
\hline \multirow[t]{2}{*}{ Câmara fria } & Alumínio & $59 \mathrm{Ba}$ & $66 \mathrm{Aa}$ & $96 \mathrm{Aa}$ & 97Aa & $93 \mathrm{Aa}$ & 94Aa & $92 \mathrm{Aa}$ & 97Aa & $95 \mathrm{Aa}$ & $93 \mathrm{Aa}$ \\
\hline & Papelão & $59 \mathrm{Ba}$ & $66 \mathrm{Aa}$ & 94Aa & $97 \mathrm{Aa}$ & $95 \mathrm{Aa}$ & 96Aa & 91Aa & 96Aa & 93Aa & 93Aa \\
\hline \multirow{3}{*}{ Ambiente } & & \multicolumn{10}{|c|}{ Envelhecimento acelerado (\%) } \\
\hline & Alumínio & 86Aa & $85 \mathrm{Aa}$ & $-^{(2)}$ & - & $94 \mathrm{Aa}$ & $92 \mathrm{Aa}$ & $96 \mathrm{Aa}$ & $93 \mathrm{Aa}$ & 81Aa & 86Aa \\
\hline & Papelão & $86 \mathrm{Aa}$ & $85 \mathrm{Aa}$ & - & - & $87 \mathrm{Aa}$ & $75 \mathrm{Bb}$ & $93 \mathrm{Aa}$ & $96 \mathrm{Aa}$ & $77 \mathrm{Aa}$ & $82 \mathrm{Aa}$ \\
\hline \multirow[t]{2}{*}{ Câmara fria } & Alumínio & $86 \mathrm{Aa}$ & $85 \mathrm{Aa}$ & - & - & $82 \mathrm{Bb}$ & $92 \mathrm{Aa}$ & $93 \mathrm{Aa}$ & $93 \mathrm{Aa}$ & $78 \mathrm{Ab}$ & $84 \mathrm{Aa}$ \\
\hline & Papelão & $86 \mathrm{Aa}$ & $85 \mathrm{Aa}$ & - & - & $92 \mathrm{Aa}$ & $95 \mathrm{Aa}$ & $95 \mathrm{Aa}$ & $94 \mathrm{Aa}$ & $90 \mathrm{Aa}$ & $91 \mathrm{Aa}$ \\
\hline \multirow{3}{*}{ Ambiente } & & \multicolumn{10}{|c|}{ Emergência das plântulas em casa de vegetação (\%) } \\
\hline & Alumínio & $95 \mathrm{Aa}$ & $94 \mathrm{Aa}$ & 94Aa & $93 \mathrm{Aa}$ & $93 \mathrm{Aa}$ & $92 \mathrm{Aa}$ & $93 \mathrm{Aa}$ & $89 \mathrm{Aa}$ & 91Aa & 89Aa \\
\hline & Papelão & $95 \mathrm{Aa}$ & 94Aa & $96 \mathrm{Aa}$ & $90 \mathrm{Ba}$ & $95 \mathrm{Aa}$ & $90 \mathrm{Aa}$ & $91 \mathrm{Aa}$ & $90 \mathrm{Aa}$ & $86 \mathrm{Ba}$ & $92 \mathrm{Aa}$ \\
\hline \multirow[t]{2}{*}{ Câmara fria } & Alumínio & $95 \mathrm{Aa}$ & 94Aa & $96 \mathrm{Aa}$ & $95 \mathrm{Aa}$ & $95 \mathrm{Aa}$ & $91 \mathrm{Aa}$ & 94Aa & $90 \mathrm{Aa}$ & $98 \mathrm{Aa}$ & $95 \mathrm{Aa}$ \\
\hline & Papelão & $95 \mathrm{Aa}$ & $94 \mathrm{Aa}$ & $99 \mathrm{Aa}$ & $97 \mathrm{Aa}$ & $93 \mathrm{Aa}$ & $94 \mathrm{Aa}$ & $90 \mathrm{Aa}$ & $93 \mathrm{Aa}$ & $96 \mathrm{Aa}$ & $92 \mathrm{Aa}$ \\
\hline
\end{tabular}

(1)Médias seguidas pela mesma letra, maiúscula na linha e minúscula na coluna, em cada período e condição de armazenamento, não diferem entre si pelo teste de Tukey, a 5\% de probabilidade. ${ }^{(2)}$ Dados não disponíveis. 
armazenamento em sementes partidas, acondicionadas em embalagem de papel aluminizado e mantidas em condições ambientais (Figura 2).

Nos testes de sanidade, foram detectados os fungos Alternaria alternata, Alternaria dauci e baixos porcentuais de outros fungos. Resultados obtidos para os fungos A. alternata e A. dauci foram analisados separadamente, pois diversos autores citam que o gênero Alternaria spp., quando associado às sementes, pode
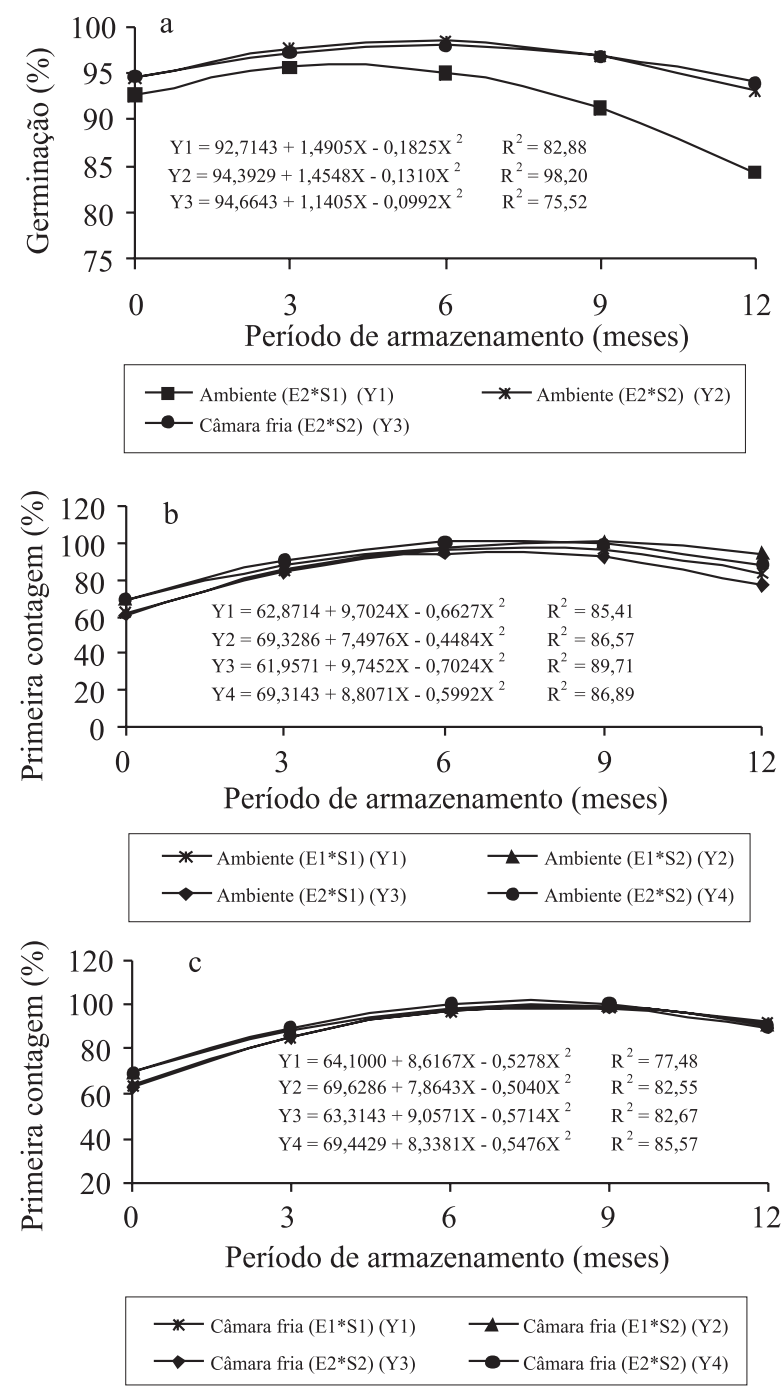

Figura 1. Estimativa da germinação (a) e do teste de primeira contagem das sementes de coentro armazenadas em condições ambientais (b) e em câmara fria (c), de acordo com o período de armazenamento, para respectivas interações com efeito de período significativo. E1: embalagem de alumínio; E2: embalagem de papelão; S1: sementes inteiras; S2: sementes partidas. causar prejuízos (Neergaard, 1977; Cunha et al., 1987; Rotem, 1995; Reis et al., 2006). Em estudos realizados com vários lotes de sementes de coentro, Reis et al. (2006) também verificaram a predominância dessas duas
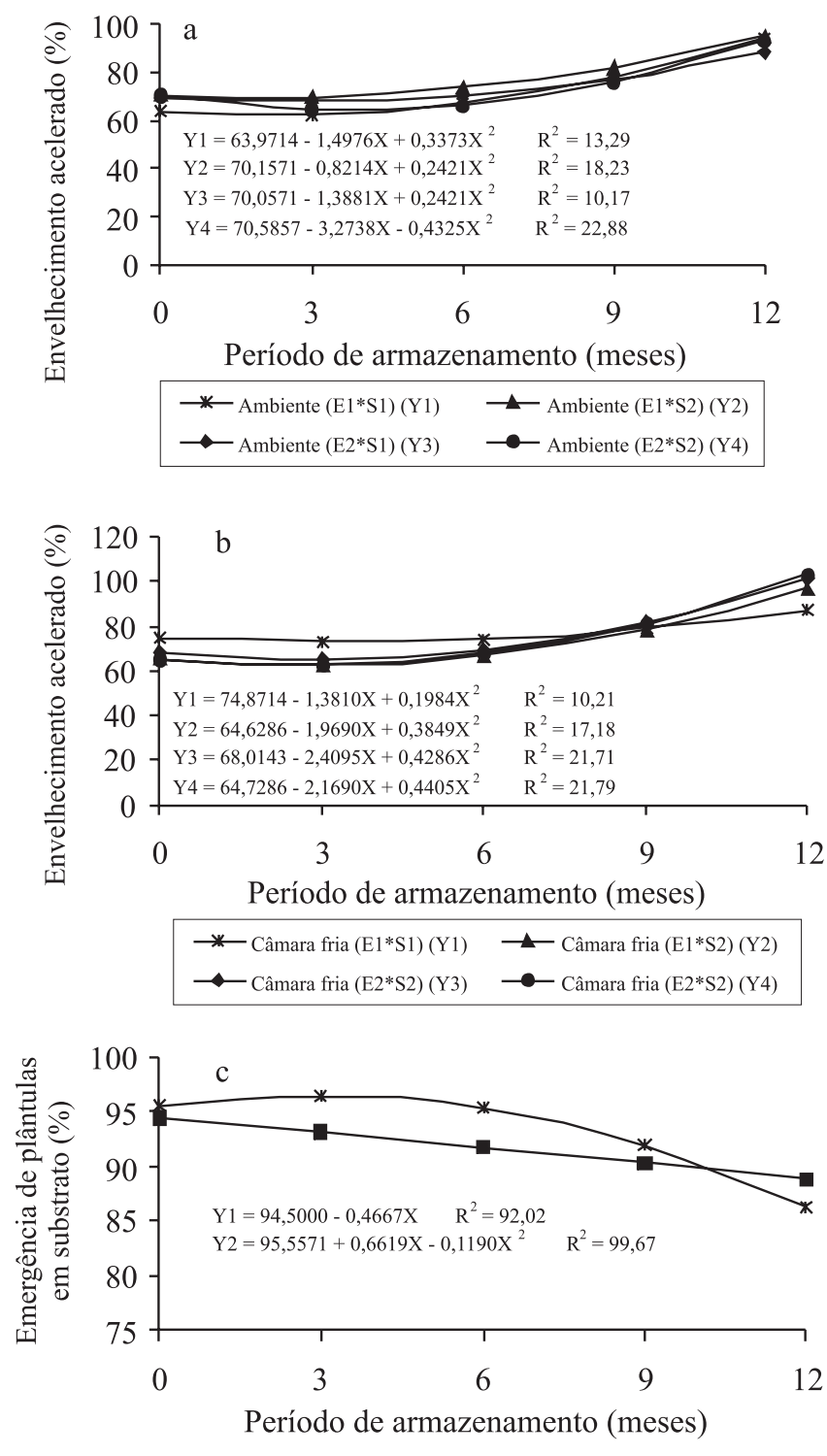

Ambiente (E1*S2) (Y1) $\rightarrow$ Ambiente (E2*S1) (Y2)

Figura 2. Estimativa do teste de envelhecimento acelerado das sementes de coentro, armazenadas em condições ambientais (a) e em câmara fria (b), e da emergência de plântulas (c) das sementes de coentro, de acordo com o período de armazenamento, para respectivas interações com efeito de período significativo. E1: embalagem de alumínio; E2: embalagem de papelão; S1: sementes inteiras; S2: sementes partidas. 
espécies de Alternaria. Os demais fungos foram analisados mediante seu somatório e enquadrados como outros fungos (Tabela 3). Houve flutuações quanto à incidência de A. alternata e A. dauci, durante o armazenamento, tanto nas sementes inteiras quanto nas partidas, bem como com relação ao tipo de embalagem utilizada.

Na análise de vários lotes de sementes de coentro, Trigo et al. (1997) observaram elevadas incidências de fungos como A. alternata, A. radicina e Fusarium spp. Segundo estes autores, trata-se de um dado preocupante, uma vez que tais fungos afetam diretamente a qualidade fisiológica das sementes de coentro, que podem revelar baixo potencial germinativo e, conseqüentemente, baixa emergência em campo. Alguns fungos como A. dauci, quando associados com sementes, podem causar prejuízos em sua formação, influenciando a qualidade fisiológica (Neergaard, 1977). A. alternata, embora seja considerado saprófita contaminante (Cunha et al., 1987), quando associado com A. dauci, pode causar danos à qualidade fisiológica das sementes e tombamento de plântulas (Muniz \& Porto, 1998). Quanto à incidência de outros fungos, observa-se que as sementes inteiras, em várias circunstâncias, apresentaram a maior incidência de tais fungos (Tabela 3).

As curvas ajustadas, relativas à incidência de A. alternata nas sementes mantidas em condições ambientais, de acordo com o período de armazenamento, mostraram que os valores decresceram linearmente ao longo do tempo (Figura 3). O mesmo fato foi observado em sementes inteiras, acondicionadas em embalagens de papel aluminizado e armazenadas em câmara fria. No entanto, as demais interações para esse fungo, obtidas em sementes mantidas em câmara fria, ajustaram-se aos modelos quadráticos de regressão.

Quanto à incidência de $A$. dauci, verifica-se que não houve efeito do período de armazenamento, em sementes inteiras acondicionadas em caixa de papelão, independentemente da condição de armazenamento. Também, não houve efeito do período de armazenamento, em sementes inteiras acondicionadas em embalagem de papel aluminizado e armazenadas em câmara fria. No que tange às demais interações (sementes $\mathrm{x}$ embalagens), observa-se que a presença de $A$. dauci apresentou acréscimos e reduções com o aumento do período de armazenamento, dependente do tipo de semente, da embalagem e das condições de armazenamento. De modo geral, a incidência de outros fungos aumentou ao longo do período de armazenamento.

No armazenamento, a preservação da qualidade das sementes justifica os esforços durante o processo de produção. Nesse sentido, medidas preventivas utilizadas para manutenção da qualidade das sementes, como por exemplo o tratamento químico com fungicidas, têm sido

Tabela 3. Valores médios obtidos no teste de sanidade, quanto à presença de Alternaria alternata, Alternaria dauci e outros fungos, de duas categorias de sementes de coentro, acondicionadas em dois tipos de embalagens e mantidas em duas condições de armazenamento, nos diferentes períodos de armazenamento ${ }^{(1)}$.

\begin{tabular}{|c|c|c|c|c|c|c|c|c|c|c|c|}
\hline \multirow{3}{*}{$\begin{array}{l}\text { Condições de } \\
\text { armazenamento }\end{array}$} & \multirow[t]{3}{*}{ Embalagem } & \multicolumn{10}{|c|}{ Período de armazenamento (meses) } \\
\hline & & \multicolumn{2}{|c|}{0} & \multicolumn{2}{|c|}{3} & \multicolumn{2}{|c|}{6} & \multicolumn{2}{|l|}{9} & \multicolumn{2}{|c|}{12} \\
\hline & & $\begin{array}{c}\text { Sementes } \\
\text { inteiras }\end{array}$ & $\begin{array}{c}\text { Sementes } \\
\text { partidas }\end{array}$ & $\begin{array}{c}\text { Sementes } \\
\text { inteiras }\end{array}$ & $\begin{array}{c}\text { Sementes } \\
\text { partidas }\end{array}$ & $\begin{array}{c}\text { Sementes } \\
\text { inteiras }\end{array}$ & $\begin{array}{l}\text { Sementes } \\
\text { partidas }\end{array}$ & $\begin{array}{c}\text { Sementes } \\
\text { inteiras }\end{array}$ & $\begin{array}{c}\text { Sementes } \\
\text { partidas }\end{array}$ & $\begin{array}{c}\text { Sementes } \\
\text { inteiras }\end{array}$ & $\begin{array}{c}\text { Sementes } \\
\text { partidas }\end{array}$ \\
\hline & & \multicolumn{10}{|c|}{ Alternaria alternata $(\%)$} \\
\hline \multirow[t]{2}{*}{ Ambiente } & Alumínio & $95 \mathrm{Aa}$ & $76 \mathrm{Ba}$ & $85 \mathrm{Aa}$ & 84Aa & 77Aa & $63 \mathrm{Ba}$ & $30 \mathrm{Ba}$ & $50 \mathrm{Aa}$ & 38Aa & 31Aa \\
\hline & Papelão & $95 \mathrm{Aa}$ & $76 \mathrm{Ba}$ & $66 \mathrm{Ab}$ & $61 \mathrm{Ab}$ & $11 \mathrm{Ab}$ & $15 \mathrm{Ab}$ & $20 \mathrm{Aa}$ & $9 \mathrm{Bb}$ & $5 \mathrm{Ab}$ & $6 \mathrm{Ab}$ \\
\hline \multirow[t]{2}{*}{ Câmara fria } & Alumínio & $95 \mathrm{Aa}$ & $76 \mathrm{Ba}$ & $83 \mathrm{Aa}$ & $90 \mathrm{Aa}$ & $86 \mathrm{Ba}$ & $95 \mathrm{Aa}$ & $90 \mathrm{Aa}$ & $96 \mathrm{Aa}$ & 71Aa & $54 \mathrm{Ba}$ \\
\hline & Papelão & $95 \mathrm{Aa}$ & $76 \mathrm{Ba}$ & $88 \mathrm{Aa}$ & 86Aa & $85 \mathrm{Aa}$ & $90 \mathrm{Aa}$ & 94Aa & $95 \mathrm{Aa}$ & $47 \mathrm{Ab}$ & $74 \mathrm{Bb}$ \\
\hline \multirow{3}{*}{ Ambiente } & & \multicolumn{10}{|c|}{ Alternaria dauci (\%) } \\
\hline & Alumínio & $38 \mathrm{Aa}$ & 48Aa & $40 \mathrm{Aa}$ & $42 \mathrm{Aa}$ & $44 \mathrm{Aa}$ & $48 \mathrm{Aa}$ & $57 \mathrm{Aa}$ & $46 \mathrm{Aa}$ & $52 \mathrm{Aa}$ & $37 \mathrm{Ba}$ \\
\hline & Papelão & $38 \mathrm{Aa}$ & $48 \mathrm{Aa}$ & $46 \mathrm{Aa}$ & $58 \mathrm{Ab}$ & $46 \mathrm{Ab}$ & $20 \mathrm{Bb}$ & $48 \mathrm{Aa}$ & $32 \mathrm{Ba}$ & $34 \mathrm{Ab}$ & $22 \mathrm{Ab}$ \\
\hline \multirow[t]{2}{*}{ Câmara fria } & Alumínio & $38 \mathrm{Aa}$ & $48 \mathrm{Aa}$ & $41 \mathrm{Aa}$ & $44 \mathrm{Aa}$ & $37 \mathrm{Ba}$ & $58 \mathrm{Aa}$ & $45 \mathrm{Aa}$ & $47 \mathrm{Aa}$ & $61 \mathrm{Aa}$ & $49 \mathrm{Ab}$ \\
\hline & Papelão & $38 \mathrm{Aa}$ & $48 \mathrm{Aa}$ & $20 \mathrm{Bb}$ & 41Aa & 41Aa & $55 \mathrm{Aa}$ & $37 \mathrm{Aa}$ & $40 \mathrm{Aa}$ & $40 \mathrm{Bb}$ & 71Aa \\
\hline \multicolumn{12}{|c|}{ Outros fungos (\%) } \\
\hline \multirow[t]{2}{*}{ Ambiente } & Alumínio & $8 \mathrm{Aa}$ & $1 \mathrm{Aa}$ & $25 \mathrm{Aa}$ & $7 \mathrm{Ba}$ & $14 \mathrm{Aa}$ & $3 \mathrm{Ba}$ & $17 \mathrm{Aa}$ & $10 \mathrm{Aa}$ & $25 \mathrm{Aa}$ & $23 \mathrm{Aa}$ \\
\hline & Papelão & $8 \mathrm{Aa}$ & $1 \mathrm{Aa}$ & $22 \mathrm{Aa}$ & $10 \mathrm{Ba}$ & $10 \mathrm{Aa}$ & $7 \mathrm{Aa}$ & $14 \mathrm{Aa}$ & $3 \mathrm{Ba}$ & $18 \mathrm{Aa}$ & $19 \mathrm{Aa}$ \\
\hline \multirow[t]{2}{*}{ Câmara fria } & Alumínio & $8 \mathrm{Aa}$ & $1 \mathrm{Aa}$ & $30 \mathrm{Aa}$ & $15 \mathrm{Ba}$ & $29 \mathrm{Aa}$ & $10 \mathrm{Ba}$ & $37 \mathrm{Aa}$ & $9 \mathrm{Ba}$ & $32 \mathrm{Aa}$ & $29 \mathrm{Aa}$ \\
\hline & Papelão & $8 \mathrm{Aa}$ & $1 \mathrm{Aa}$ & $29 \mathrm{Aa}$ & $12 \mathrm{Ba}$ & $19 \mathrm{Ab}$ & $7 \mathrm{Ba}$ & $15 \mathrm{Ab}$ & $4 \mathrm{Ba}$ & $26 \mathrm{Aa}$ & $26 \mathrm{Aa}$ \\
\hline
\end{tabular}

(1)Médias seguidas pela mesma letra, maiúscula na linha e minúscula na coluna, em cada período e condição de armazenamento, não diferem entre si pelo teste de Tukey, a 5\% de probabilidade. 

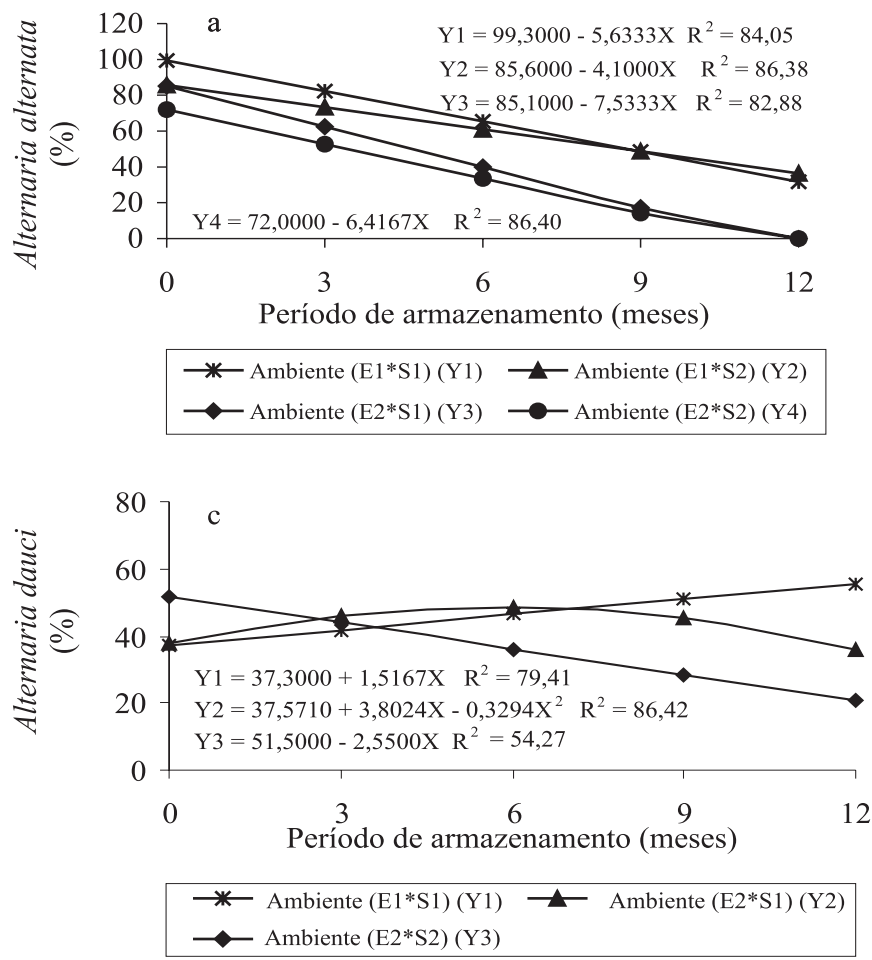
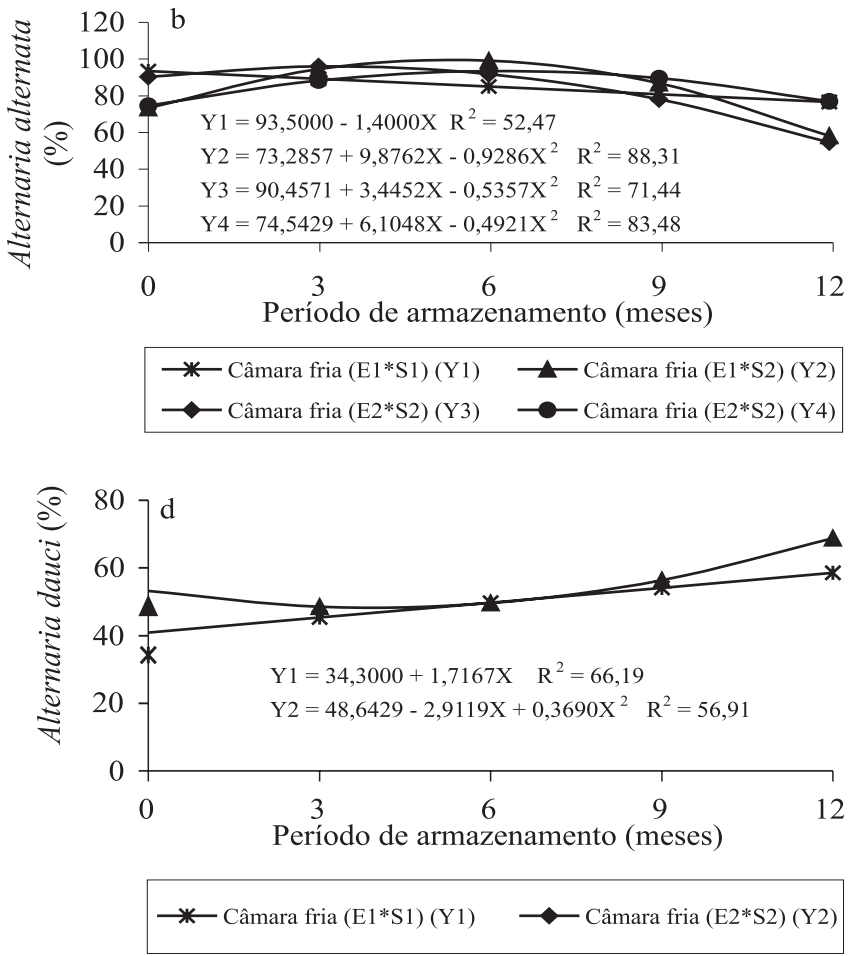

Figura 3. Estimativa da incidência de Alternaria alternata em sementes de coentro, armazenadas em condições ambientais (a) e em câmara fria (b), e de Alternaria dauci em sementes de coentro, armazenadas em condições ambientais (c) e em câmara fria (d), de acordo com o período de armazenamento, para respectivas interações com efeito de período significativo. E1: embalagem de alumínio; E2: embalagem de papelão; S: sementes inteiras; S2: sementes partidas.

adotadas como um procedimento rotineiro. Embora a principal finalidade desse tratamento esteja associada à proteção contra microrganismos do solo, o tratamento pode, também, controlar fungos relacionados à deterioração das sementes durante o armazenamento.

\section{Conclusões}

1. A colheita mecânica apresenta maior porcentagem de sementes partidas.

2. Sementes inteiras colhidas mecanicamente apresentam maior vigor que as sementes inteiras colhidas manualmente.

3. Sementes de coentro conservam a sua qualidade até um ano, independentemente das condições de armazenamento.

4. No armazenamento em condições ambientais, as sementes devem ser acondicionadas em embalagens impermeáveis.

5. Sementes partidas apresentam potencial para o estabelecimento da cultura de coentro.

\section{Referências}

ASSOCIATION OF OFFICIAL SEED ANALYSTS (East Lasing, Estados Unidos). Seed vigor testing handbook. East Lasing, 1983. 88p. (Contribution, 32).

BEE, R.A.; BARROS, A.C.S.A. Sementes de abóbora armazenadas em condições de vácuo. Revista Brasileira de Sementes, v.21, p.120-126, 1999.

BRASIL. Ministério da Agricultura e Reforma Agrária. Regras para análise de sementes. Brasília: SNDA/DNDV/CLAV, 1992. 365p.

CANEPPELE, M.A.B.; SILVA, R.F.; ALVARENGA, E.M.; CAMPELO JÚNIOR, J.H.; CARDOSO, A.A. Influência da embalagem, do ambiente e do período de armazenamento na qualidade de sementes de cebola (Allium cepa L.). Revista Brasileira de Sementes, v.17, p.249-257, 1995.

CARVALHO, N.M.; NAKAGAWA, J. Sementes: ciência, tecnologia e produção. 4.ed. Jaboticabal: Funep, 2000. 588p.

CROCHEMORE, M.L. Conservação de sementes de tremoço azul (Lupinus angustifolius L.) em diferentes embalagens. Revista Brasileira de Sementes, v.15, p.227-231, 1993.

CUNHA, M.M.; REIFSCHNEIDER, F.J.B.; VECHIA, P.T. Aspectos fitossanitários na produção de sementes de cenoura. Horticultura Brasileira, v.5, p.11-14, 1987. 
DELOUCHE, J.C.; BASKIN, C.C. Accelerated aging techniques for predicting the relative storability of seed lots. Seed Science and Technology, v.1, p.427-452, 1973.

DELOUCHE, J.C.; MATTHES, R.K.; DOUGHERTY, G.M.; BODY, A.H. Storage of seed in sub-tropical and tropical regions. Seed Science and Technology, v.1, p.671-700, 1973.

JIANHUA, Z.; McDONALD, M.B. The satured salt accelerated aging for small-seeded crops. Seed Science and Technology, v.25, p.123-131, 1996.

MARCOS FILHO, J. Teste de envelhecimento acelerado. In: KRZYZANOWSKI, F.C.; VIEIRA, R.D.; FRANÇA NETO, J.B. (Ed.). Vigor de sementes: conceitos e testes. Londrina: Abrates, 1999. p.1-24.

MASCHIETTO, R.W.; NOVEMBRE, A.D.L.C.; SILVA, W.R. Métodos de colheita e qualidade das sementes de capim colonião cultivar Mombaça. Bragantia, v.62, p.291-296, 2003.

MUNIZ, M.F.B.; PORTO, M.D.M. Flutuação populacional e sobrevivência de Alternaria spp. em sementes de cenoura. Revista Brasileira de Sementes, v.20, p.449-453, 1998.

NASCIMENTO, W.M. Cresce o consumo de sementes de coentro. SeedNews, v.8, p.14, 2004.

NASCIMENTO, W.M.; PESSOA, H.B.S.V.; BOITEUX, L.S. Qualidade fisiológica de sementes de milho-doce submetidas a diferentes processos de colheita, debulha e beneficiamento. Pesquisa Agropecuária Brasileira, v.29, p.1211-1214, 1994.

NEERGAARD, P. Seed pathology. London: The MacMillan Press, 1977. v.2, 1191p.
OLADIRAN, J.A.; AGUNBIABE, S.A. Germination and seedling development from pepper (Capsicum annuum L.) seeds following storage in different packaging materials. Seed Science and Technology, v.28, p.413-419, 2000.

PEREIRA, R.S.; MUNIZ, M.F.B.; NASCIMENTO, W.M. Aspectos relacionados à qualidade de sementes de coentro. Horticultura Brasileira, v.23, p.703-706, 2005.

REIS, A.; SATELIS, J.F.; PEREIRA, R.S.; NASCIMENTO, W.M. Associação de Alternaria dauci e A. alternata com sementes de coentro e eficiência do tratamento químico. Horticultura Brasileira, v.24, p.107-111, 2006.

ROTEM, J. The genus Alternaria. St. Paul: The American Phytopathological Society, 1995. 326p.

TORRES, S.B. Qualidade de sementes de melancia armazenadas em diferentes embalagens e ambientes. Revista Ciência Agronômica, v.36, p.163-168, 2005.

TORRES, S.B.; SILVA, M.A.S.; RAMOS, S.R.; QUEIRÓZ, M.A. Qualidade de sementes de maxixe armazenadas em diferentes embalagens e ambientes. Ciência e Agrotecnologia, v.26, p.539544, 2002.

TRIGO, M.F.O.O.; TRIGO, L.F.N.; PIEROBOM, C.R. Fungos associados às sementes de coentro (Coriandrum sativum L.) no Rio Grande do Sul. Revista Brasileira de Sementes, v.19, p.214-218, 1997.

VIGGIANO, J. Produção de sementes de algumas umbelíferas. Informe Agropecuário, v.10, p.60-65, 1984. 